\title{
Mourning the Death of a Foreign Child
}

\author{
Alberto Stefana ${ }^{1}$ \\ Received: 22 July 2016/Accepted: 16 November 2016 / Published online: 29 November 2016 \\ (C) Dr. K C Chaudhuri Foundation 2016
}

To the Editor: North-American and Western European societies are multicultural. This affects hospital and outpatient organizations: the hospitalizations of patients coming from totally different cultural contexts are becoming more and more frequent. Among the hospitalized patients, there are also newborns and infants. Unfortunately, some of them do not survive. The importance of this phenomenon should not be underestimated [1].

Ways of dealing with death and mourning are closely related to collective and cultural characteristics of a society, which possesses its own collective language to express emotions [2]. It is also known that, in every age and cultural setting, there is always a potential for individual emotional variability [3], which also depends on the sexual gender of the grieving person [4].

At first glance, the reactions to the death of a child and the stages of the grieving process do not show substantial dissimilarities in people that belong to and/or embrace cultures or religions that are totally different from one another. Many foreign parents seem to have deserted their ancestral death rituals replacing them with those of Western origin. But if we look beyond appearances, we are able to discover that this phenomenon is just the (superficial) result of a process of adaptation to the Western cultural environment into which the parents of the hospitalized child have immigrated. Foreign parents do adapt (probably worrying about being judged) to Western culture, but these adopted reactions to

Alberto Stefana

alberto.stefana@email.it

1 Department of Human Science, University of Verona, Verona, Italy death as well as the modes and taboos of mourning, manifest themselves in ways that do not belong to them. It is therefore possible to state that beneath this 'westernized' appearance lies a quintessentially different reality, one deeply infused with the beliefs and precepts of the culture of origin.

To make it possible for professionals to create for the parents a sufficiently suitable environment in which to deal with the loss of their child and begin the work of mourning, they must acquire specific knowledge about the customs and traditions of the parents' culture of origin. This is not a task to be regulated or standardized on the basis of protocols and precedents. It must be 'customized' to fit each specific case.

\section{Compliance with Ethical Standards}

Conflict of Interest None.

Source of Funding None.

\section{References}

1. Liu L, Johnson HL, Cousens S, et al.; Child Health Epidemiology Reference Group of WHO and UNICEF. Global, regional, and national causes of child mortality: an updated systematic analysis for 2010 with time trends since 2000. Lancet. 2012;379:2151-61.

2. Klass D. Developing a cross-cultural model of grief: the state of the field. Omega. 1999a;39:153-78.

3. Carroll M. Infant death and burials in roman Italy. J Roman Archaeol. 2011;24:99-120.

4. Kavanaugh K. Gender differences among parents who experience the death of an infant weighing less than 500 grams at birth. Omega. 1997;35:281-96. 